\title{
Homoarginine and ornithine production during C2C12 myogenic differentiation
}

\author{
Alexandr Zhloba ${ }^{1}$, Tatiana Subbotina ${ }^{1}$, Stanislava Prikhodko ${ }^{2}$, \\ Alexandr Khudiakov', Natalia Smolina ${ }^{2,3}$, and Anna Kostareva2,3,4 \\ ${ }^{1}$ Biochemical Department of Scientific Centre, First Pavlov State Medical University of \\ St. Petersburg, St. Petersburg, Russian Federation \\ ${ }^{2}$ Institute of Molecular Biology and Genetics. Federal Almazov North-West Medical Research \\ Centre, Saint Petersburg, Russian Federation \\ 3ITMO University, Saint Petersburg, Russian Federation \\ ${ }^{4}$ Department of Women's and Children's Health. Karolinska Institutet, Stockholm, Sweden \\ Address correspondence and requests for materials to Stanislava Prikhodko, \\ stanislava.prikhodko@gmail.com
}

Citation: Zhloba, A., Subbotina, T., Prikhodko, S., Khudiakov, A., Smolina, N., and Kostareva, A. 2018. Homoarginine and ornithine production during $\mathrm{C} 2 \mathrm{C} 12$ myogenic differentiation. Bio. Comm. 63(3): 174-179. https://doi.org/10.21638/ spbu03.2018.303

Author's information: Alexandr A Zhloba, MD, PhD, Head of Department, https://orcid.org/0000-0003-0605-7617; Tatiana F. Subbotina, MD, PhD, Head of Laboratory, https://orcid.org/0000-00022278-8391: Stanislava S. Prikhodko, MSc, Junior Researcher, https://orcid.org/0000 0001-7018-6398; Alexandr A. Khudiakov, Ph.D., Researcher; Natalia A. Smolina, PhD, Researcher, https://orcid.org/0000-00023339-0688; Anna A. Kostareva, MD, PhD, Director of Institute, https://orcid.org/00000002-9349-6257

Manuscript Editor: Dunja Knapp, DFG-Center for Regenerative Therapies Dresden, Technische Universität Dresden, Germany

Received: September 25, 2018;

Revised: October 22, 2018;

Accepted: October 23, 2018;

Copyright: (c) 2018 Zhloba et al. This is an open-access article distributed under the terms of the License Agreement with Saint Petersburg State University, which permits to the authors unrestricted distribution, and self-archiving free of charge.

Funding: This work was supported by the Russian Science Foundation (14-15-00745 $)$.

Competing interests: The authors have declared that no competing interests exist.

\begin{abstract}
Assessment of cellular rates of amino acid consumption and release in vitro allows the study of cell culture in a time-course experiment without any cell damage. Determination of the release of amino acid metabolites that initially were not present in the media provides more reliable information about the processes of growth and differentiation in comparison with determination of amino acid consumption rates. Homoarginine (hArg), a derivative of arginine, is generated as the minor product in the reaction catalyzed by L-Arginine: glycine amidinotransferase, where L-lysine serves as an acceptor for amidine group instead of glycine. Ornithine is another product generated in this reaction from arginine. Thus, the goal of the present study was to evaluate the rate of hArg and ornithine accumulation in comparison to the rate of consumption of other amino acids in the course of $\mathrm{C} 2 \mathrm{C} 12$ myoblast differentiation. The release time profiles were similar for hArg and ornithine, with the maximum corresponding to the second day of differentiation. The shift for hArg at this time point was detected with greater reliability $(p<0.002)$ than for ornithine and other amino acids. We suggest that hArg and ornithine could serve as markers to monitor the processes of myoblasts growth and differentiation.
\end{abstract}

Keywords: amino acids, homoarginine, myogenic differentiation, ornithine.

\section{Introduction}

The consumption of amino acids by cell cultures characterizes their metabolism and therefore could be used to assess the development of cell culture. Determination of amino acid intake is important to have an idea about the assimilation processes in the progress of cell development, which will allow optimization or creation of new culture media, cell production for cell therapies, in modern biotechnology, or in basic research (Hong, Wheat, Mazzeo, and Diehl, 2007; CarilloCocom et al., 2015; Salazar, Keusgen, and von Hagen, 2016). Estimation of amino acid consumption from cell milieu provides information in a time-course experiment without cell damage or interference in the cell mass area (Carillo-Cocom et al., 2015; Salazar, Keusgen, and von Hagen, 2016). The cell culture media contains large excesses of essential and conditionally essential amino acids, thus their consumption by cells may be only a small percentage of the total, which means that an evaluation of their decrease is not accurate enough. The determination of metabolites or derivatives of amino acids that initially were not included in the media could provide more reliable information about the growth and differentiation of cell culture. Homoarginine (hArg) is known as an unusual derivative of arginine. In animal tissues it is generated additionally to guanidine acetic acid in a 
reaction catalyzed by L-Arginine: glycine amidinotransferase [AGAT; EC 2.1.4.1] (März et al., 2010; Drechsler et al., 2011; Atzler et al., 2014). Therefore, hArg content in culture media could be a marker of cell growth. In human and animal tissues hArg is formed in the AGAT reaction, where L-lysine serves as an acceptor of amidine group instead of glycine. Ornithine is another product which is generated in this reaction from arginine ( $\mathrm{Da}-$ vids et al., 2012; Choe et al., 2013). Human AGAT is expressed in various tissues. It is highly expressed in the kidneys and pancreas; with less extension in skeletal muscles, the myocardium and the brain (Van Pilsum, Stephens, and Taylor, 1972; Cullen et al., 2006).

C2C12 murine myoblasts represent a widespread experimental model to study skeletal muscle growth and differentiation in vitro (Yaffe and Saxel, 1977). Moreover, expression of AGAT was observed in rodent muscle tissue during embryogenesis (Braissant et al., 2005); therefore, this model was chosen for the present study. AGAT expression was remarkably reduced in differentiated cells in comparison to non-differentiaed cells (Braissant et al., 2005; Sandell, Guan, Ingram, and Tilghman, 2003). Examination of hArg accumulation in the course of myoblast differentiation into myotubes hasn't been performed yet.

The goal of the present study was to evaluate the rate of hArg and ornithine accumulation in comparison with rates of consumption of other amino acids in the course of $\mathrm{C} 2 \mathrm{C} 12$ myoblast differentiation into myotubes.

\section{Materials and Methods}

\section{CULTIVATION OF C2C12 CELLS}

The $\mathrm{C} 2 \mathrm{C} 12$ cell line, representing mouse adherent myoblasts, was a kind gift from Prof. Thomas Sejersen (Group of myopathy research, Karolinska Institutet, Stockholm, Sweden). The cells were seeded at $2 \times 10^{5}$ cells/well in 6-well plates and cultivated for $72 \mathrm{~h}$ in $2 \mathrm{ml} /$ well of growth media (GM: DMEM (Invitrogen, USA, 41966-29) supplemented with heat-inactivated $10 \%$ fetal calf serum, $4 \mathrm{mM}$ glutamine, and $1 \%$ penicillin-streptomycin (all from Invitrogen, USA)). The cultivation was performed in the incubator at $37^{\circ} \mathrm{C}, 5 \%$ $\mathrm{CO}_{2}, 99 \%$ humidity.

\section{MYOGENIC DIFFERENTIATION}

C2C12 myogenic differentiation was performed according to the protocol developed by Keire (Keire et al., 2013). To induce differentiation, the growth media was removed, cells were washed once with pre-warmed phosphate-buffered saline (PBS), and then $2 \mathrm{ml} /$ well of differentiation media (DM: DMEM supplemented with $2 \%$ horse serum (Gibco, USA), $4 \mathrm{mM}$ glutamine, and $1 \%$ penicillin-streptomycin) was added. Sampling DM for analysis and its complete replacement after washing with PBS were performed every $48 \mathrm{~h}$ (first time after $72 \mathrm{~h}$ of cultivation). Thus, we obtained samples of the culture media at differentiation days 0 (induction), 2, $4,7,9$, and 11. Samples were immediately frozen and stored prior to analysis at $-80{ }^{\circ} \mathrm{C}$. Control of myogenic differentiation was performed by immunofluorescence staining of desmin, myosin heavy chains, myogenin and mitofusin. The amino acid composition of samples was compared with that of corresponding basal media: GM (day 0 ) or DM (other days).

\section{SAMPLE PREPARATION}

Samples were deproteinized by mixing $100 \mu \mathrm{l}$ aliquots with $175 \mu \mathrm{l}$ ice-cold methanol acidified with $0.2 \%$ formic acid and containing norvaline as an internal standard. The tubes were centrifuged at $3000 \times g$ and $5{ }^{\circ} \mathrm{C}$ for $20 \mathrm{~min}$ after $30 \mathrm{~min}$ incubation at $-20^{\circ} \mathrm{C}$. The supernatant was directly used for amino acid analysis.

\section{AMINO ACID HPLC ANALYSIS}

Plasma amino acid profiles were determined by means of reversed phase HPLC with the help of Agilent 1100 chromatograph involving quaternary pump, autosampler and fluorescent detector, using $3.5 \mu \mathrm{m}$ Zorbax Eclipse AAA C18 column $(4.6 \times 150) \mathrm{mm}$ (Agilent Part No 963400902) with corresponding precolumn. Ortho-phthalic aldehyde (OPA) of amino acid derivatives was loaded on the column following recommendations of the supplier Agilent Technologies (Henderson, 2000) in our modification, which allowed us to determine with sufficient accuracy the concentrations of homoarginine and ornithine. Briefly, the reaction for preparing ortho-phthalic derivatives was performed on-line using the Agilent 1100 autosampler by mixing $2.5 \mu \mathrm{l}$ of borate buffer, $0.5 \mu \mathrm{l}$ of o-phthalaldehyde reagent (OPA) and $0.5 \mu \mathrm{l}$ of the sample. After 6-times stirring in the seat of the autosampler and a 0.1 min delay, fluorescent derivatives of amino acids were injected in the stream. The elution was carried out at $1.5 \mathrm{ml} / \mathrm{min}$ and $40^{\circ} \mathrm{C}$ in mobile phase gradient by mixing solutions: A) $40 \mathrm{mM}$ sodium phosphate buffer, $\mathrm{pH}$ 7.8, and B) acetonitrile: methanol: water (45:45:10). The content of solution B increased from $1.5 \%$ to $10 \%$ by min 0.1 and then from 10 to $14 \%$ by min 11 , then it reached $20 \%$ by min 15 , and $60 \%$ by min 26 . After minutes of flushing by $100 \%$ solution B, the column was equilibrated for minutes by starting phase mixture containing $1.5 \%$ of solution B. Fluorescence of the amino acid-OPA derivatives was monitored at excitation and emission wavelengths of 340 and $450 \mathrm{~nm}$, respectively. Amino acid concentrations were expressed per $1 \mathrm{ml}$ of plasma using norvaline as an internal standard.

In our modification of the method, the hArg peak was eluted with good resolution between the peaks of Ala 


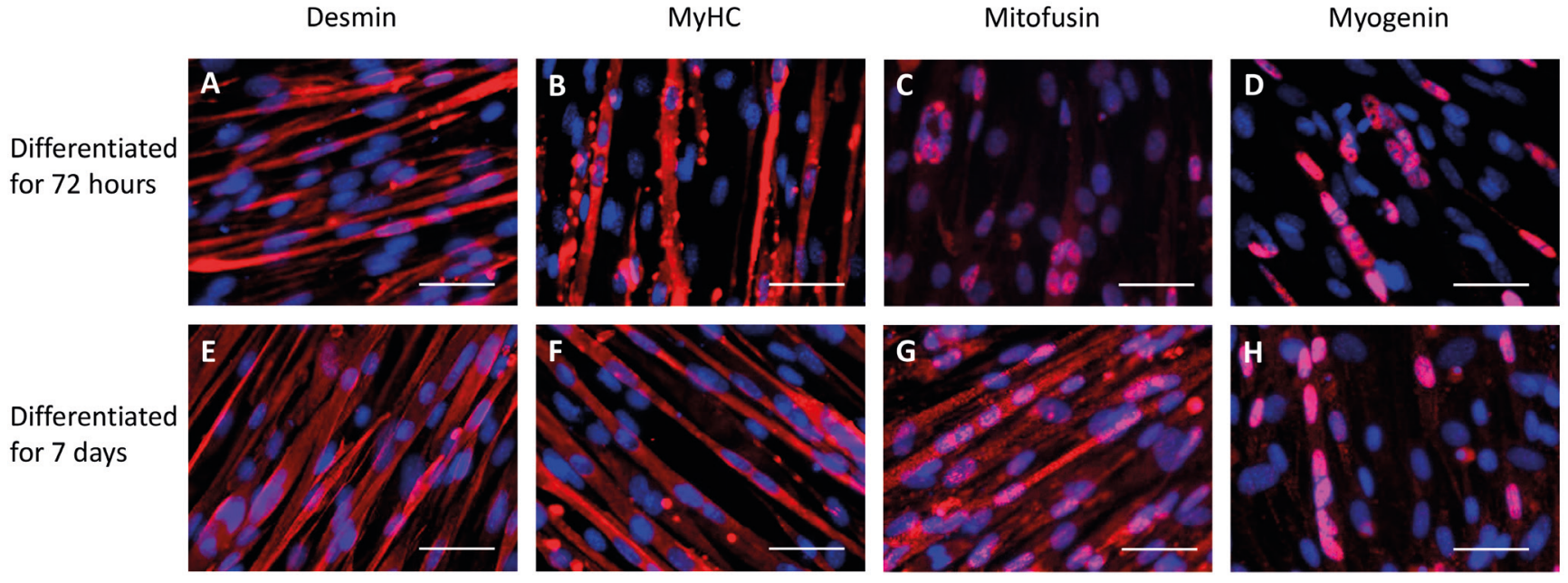

Fig. 1. Immunofluorescence of $\mathrm{C} 2 \mathrm{C} 12$ myotubes differentiation. $\mathrm{C} 2 \mathrm{C} 12$ myotubes differentiated for 72 hours (A-D) and 7 days (E-H) express proteins typical to late stages of muscle differentiation, e.g., $(A, E)$ sarcomere proteins desmin, (B,F) MyHC (myosin heavy chain), (C,G) mitochondrial protein mitofusin and $(D, H)$ muscle specific transcriptional factor myogenin. All differentiation markers are shown in red. Nuclei were stained with DAPI. Scale bar corresponds to $50 \mu \mathrm{m}$.

and Tyr, whereas the ornithine peak was between Ile and Leu. The elution of the remaining amino acids was perfomed according to Agilent's protocol (Henderson, 2000). In separate experiments, the limit of quantification (LOQ) of hArg in plasma samples was defined as LOQ $=0.20 \pm$ $0.005 \mu \mathrm{mol} / \mathrm{L}$. The coefficient of analytical variation was equal to $3.1 \%(n=10)$. These analytical characteristics are quite close to another HPLC-based method without solidphase extraction recently published by Hou et al. in 2015 .

\section{IMMUNOFLUORESCENCE}

Cells were fixed in $4 \%$ paraformaldehyde for $10 \mathrm{~min}$ at $4^{\circ} \mathrm{C}$ and then permeabilized with $0.05 \%$ Triton X-100 for $5 \mathrm{~min}$. Nonspecific binding was blocked by incubation of permeabilized cells in $15 \%$ FCS for $30 \mathrm{~min}$. Cells were incubated for one hour at room temperature with the following primary antibodies: anti-desmin (D33, DAKO, Denmark), anti-myosin heavy chain (MAB4470, R\&D, USA), anti-mitofusin 2 (ab56889, Abcam, USA). The secondary antibodies conjugated with Alexa Fluor 546 (Molecular Probes, USA) were applied for $45 \mathrm{~min}$ at room temperature. Nuclei were counterstained with DAPI (Molecular Probes, USA).

\section{DATA ANALYSIS}

To evaluate the release of amino acids (increase) to or their consumption (decrease) from the cultivation media, the concentration of amino acid found in the sample was subtracted from the concentration found in the appropriate basal media (GM or DM). The amino acid release/consumption rates were calculated by multiplying the resulting difference to the volume of the incubation media and dividing by the number of days of incubation for the given period of time ( 2 or 3 days); it was ex- pressed as nmol/day per $2 \times 10^{5}$ of primary seeded cells. Data are expressed as mean \pm s.e.m. from two independent experiments with three technical replicates $(n=6)$. The compliance of data with the normal distribution was checked by Shapiro-Wilk's W test. The significance of differences was assessed by Student's t-test for paired data, since all the data were normally distributed. The level of significance was set at $p<0.05$. Statistical analysis was performed using Statistica 10 software.

\section{Results}

Immunocytochemistry confirmed that myotubes formed from $\mathrm{C} 2 \mathrm{C} 12$ cells expressed proteins typical to late stages of muscle differentiation, e.g., sarcomere proteins desmin and MyHC (Fig. 1A, E, B, F). Staining with anti-mitofusin 2 antibody to visualize mitochondria revealed a patchy staining in myotubes, confirming the well-developed mitochondrial network forming during the myotubes maturation (Fig. 1C, G). Moreover, the muscle-specific transcriptional factor myogenin, required for the proper differentiation of most myogenic precursor cells during myogenesis, was revealed (Fig. 1D, H). We did not observe a noticeable deterioration in cell viability during cell differentiation.

Cultivation media based on DMEM contains an excessive amount of all essential and several nonessential (glutamine, serine, glycine, tyrosine, cysteine) amino acids. However, the amino acid composition of the GM and DM were slightly different, primarily due to the different amounts of serum additives and their source (10\% FCS in GM and $2 \%$ HS in DM). Nonessential amino acids, except for those mentioned above which were contained in the media in small amounts, and derivatives of arginine, i.e. citrulline, ornithine, and 
A

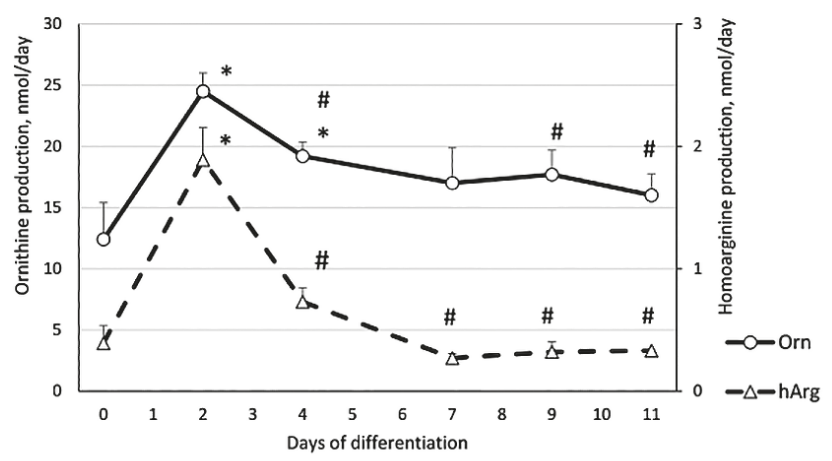

C

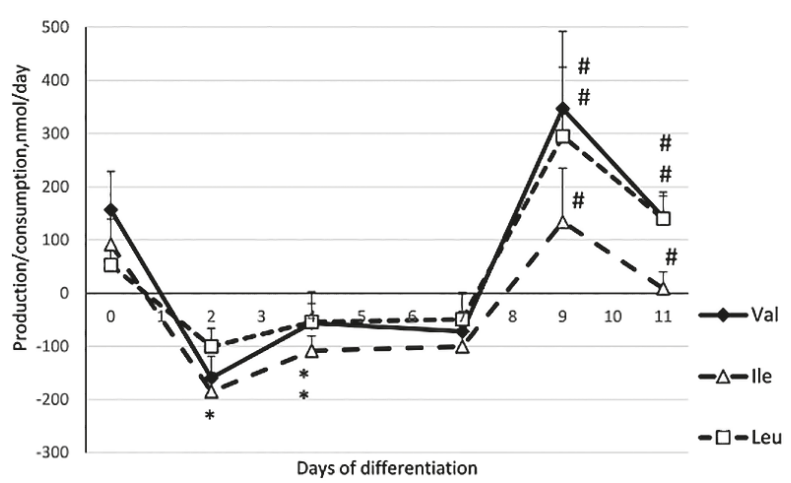

B

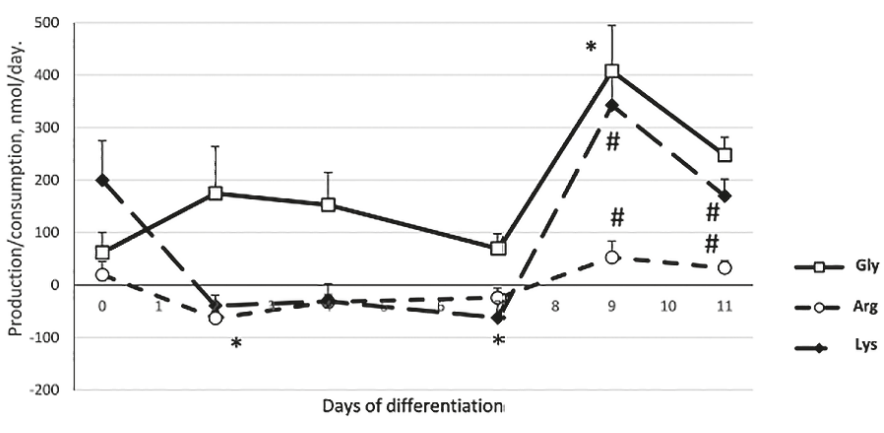

D

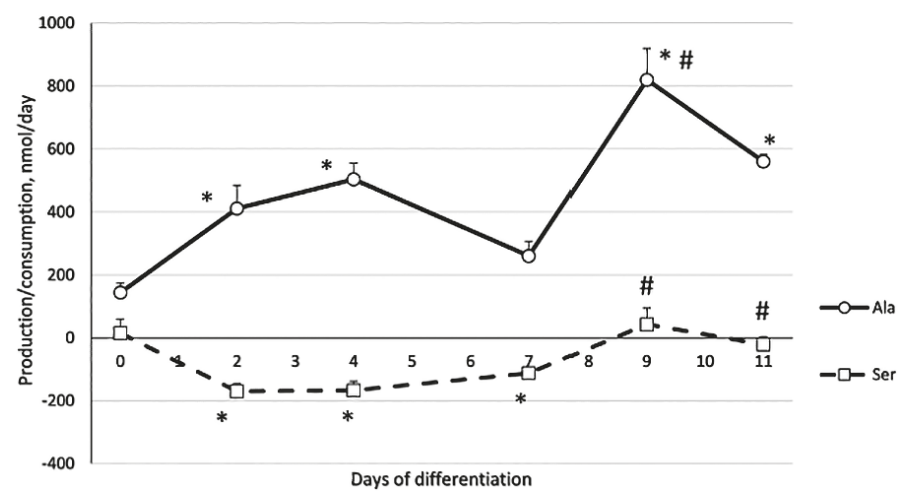

Fig. 2. Rates of the release (positive values) or consumption (negative values) of some amino acids to/from cultivation media during C2C12 differentiation. Means (s.e.m.) of six experiments are shown. The significance of differences was estimated using Student's t-test: * — p<0.05 compared to day $0, \#-\mathrm{p}<0.05$ compared to day 2 .

hArg, were found in the GM at a minimal level, but were not detected in the DM.

The data presented in Fig. 2A and in Table 1 show that the derivatives of arginine (hArg, ornithine, and citrulline) were released into the media in the course of myotubes development. The time course of the release rate were similar for hArg and ornithine, with a maximum corresponding to the second day of differentiation. It should be noted that the shift for hArg at this time point was detected with greater reliability $(p<0.002)$ than for ornithine and other amino acids. As early as day 4, the release of hArg was significantly reduced compared to day 2 and further was maintained at the minimal level.

There is a positive correlation between the daily production of hArg and ornithine $(\mathrm{r}=0.53 ; \mathrm{p}=0.008)$, but not with the consumption rate of other amino acids, including those metabolically related to hArg (Arg, Lys, and Gly (Fig. 2B)). Among the essential, the branchedchain amino acids (Val, Leu, and Ile) were most intensively consumed from the media until day 7 of differentiation, and then their simultaneous release into the me-

Table 1. The range of amino acid concentration shift $(\mu \mathrm{M})$ increment in $(+)$ or consumption from (-) the cultivation media compared with basal media composition

\begin{tabular}{|c|c|c|c|c|c|c|c|c|}
\hline \multirow{3}{*}{$\begin{array}{l}\text { Amino } \\
\text { acids }\end{array}$} & \multicolumn{2}{|c|}{ Amino acid concentration $(\mu \mathrm{M})$} & \multirow{2}{*}{\multicolumn{6}{|c|}{$\begin{array}{c}\text { Amino acid shift }(\mu \mathrm{M}) \\
\text { Days of differentiation }\end{array}$}} \\
\hline & \multirow{2}{*}{$\begin{array}{c}\text { Growth } \\
\text { media, } n=3\end{array}$} & \multirow{2}{*}{$\begin{array}{l}\text { Differentiation } \\
\text { media, } n=3\end{array}$} & & & & & & \\
\hline & & & 0 & 2 & 4 & 7 & 9 & 11 \\
\hline $\operatorname{Arg}$ & $412(12)^{2}$ & $406(17)^{2}$ & $\begin{array}{c}29(68) \\
p_{\text {all }}>0.05\end{array}$ & $\begin{array}{l}-63(25) \\
p_{11}<0.05\end{array}$ & $-12(28)$ & $-35(47)$ & $53(61)$ & $33(27)$ \\
\hline hArg & $1.51(0.08)^{1}$ & n.d. ${ }^{3}$ & $\begin{array}{c}0.58(0.25) \\
p_{2}=0.009\end{array}$ & $\begin{array}{c}1.85(0.22) \\
\mathrm{p}_{4,7,9,11}<0.002\end{array}$ & $\begin{array}{l}0.73(0.09) \\
p_{9,11}<0.03\end{array}$ & $\begin{array}{c}0.40(0.06) \\
p_{9}=0.02\end{array}$ & $0.32(0.10)$ & $0.33(0.00)$ \\
\hline Cit & $13(0.05)^{1}$ & $1.0(0.07)^{1}$ & $\begin{array}{c}-4.1(1.2) \\
\mathrm{p}_{2,4,7,9,11}<0.008\end{array}$ & $\begin{array}{c}3.9(0.7) \\
p_{9,11}<0.0001\end{array}$ & $\begin{array}{c}2.7(0.5) \\
p_{9,11}<0.0003\end{array}$ & $\begin{array}{c}4.6(1.2) \\
p_{9,11}<0.007\end{array}$ & $152(29)$ & $73(2.5)$ \\
\hline Orn & $20(1.2)^{1}$ & n.d. ${ }^{3}$ & $\begin{array}{c}19(5.2) \\
p_{\text {all }}>0.05\end{array}$ & $\begin{array}{c}25(1.2) \\
\mathrm{p}_{4,9,11}<0.02\end{array}$ & $19(0.9)$ & $25(5.0)$ & $18(2.3)$ & $16(2.0)$ \\
\hline
\end{tabular}


dia was observed (Fig. 2C). The use of branched-chain amino acids in biosynthetic processes was confirmed by morphology. The formation of significant amounts of myosin heavy chain was observed at $72 \mathrm{~h}$ after induction of differentiation, and by day 7 myosin became more aligned, forming myofibrills. We observed an unusually high release of most amino acids (especially essential amino acids and citrulline) by differentiation days 9-11. On differentiation day 9, the concentration of essential amino acids exceeded their initial content in the differentiation media by approximately 1.3 times (Fig. 2C). The time course of non-essential amino acids involved in energy metabolism during myogenic differentiation of $\mathrm{C} 2 \mathrm{C} 12$ myoblasts differed. A high initial concentration of Gln (4000 uM) fell by about two times after each replacement of the media, including on days 9 and 11 (Fig. 2D), whereas alanine, which was presented in the differentiation media in minimal amounts, was constantly released into the media in high concentration throughout the entire experiment.

Values are given in $\mu \mathrm{M}$ and represent means of six experiments; s.e.m. is given in parentheses. Data from day 0 corresponding the differentiation induction are compared with the content of growth media, while data from the others were compared with content of differentiation media. Superscript indexes specify the origination of AA: 1 - from serum supplementation only, 2 - from both DMEM and supplementation, 3 - not determined. The significance of differences was estimated using Student's t-test.

\section{Discussion}

Obtained results indicate that the consumption of essential amino acids found until day 7 of differentiation was due to their participation in the synthesis of specific muscle proteins. The peak of amino acid flux from the media was observed on day 2 of differentiation, which corresponded to the immunofluorescent data showing biosynthesis of substantial amounts of myosin heavy chain (Fig. 1B,F). However, it was tricky to use the consumption level of essential amino acids (e.g., branched-chain amino acids, see Fig. 2B) for monitoring cell growth, since the cultivation media contained a lot of them, and therefore their decrease from the baseline level was not drastic. The assimilation of certain other amino acids was significant throughout the period of observation. For example, the glutamine level decreased significantly at day 7 of cell differentiation, and the same at days 9-11 was shown, while others amino acid intake was not detected. The concentration of alanine increased permanently in the medium, starting from the second day of differentiation. This was apparently caused primarily by its participation in energy metabolism, rather than the expression of new proteins in the cell culture, since alanine was mainly synthesized in the course of transamination reactions which involved pyruvic acid and other amino acids. It should be noted that the concentration of pyruvic acid in the media was about $1 \mathrm{mM}$. Thus, the alanine determination was less suitable than the determination of glutamine in cell media for cellular differentiation monitoring. An increased level of amino acid (both essential and nonessential) in the media could be regarded as a sign of the completion of cellular differentiation and the activation of programmed cell death processes which are typical for highly differentiated C2C12 myoblasts (Burattini et al., 2004). In the present study, we showed that the release of arginine derivatives may be determined with greater reliability than the consumption of starting amino acid from the medium, including arginine. The most significant shift in the course of $\mathrm{C} 2 \mathrm{C} 12$ differentiation was found for hArg compared to other arginine derivatives, i.e., ornithine or citrulline (Table 1). Observed alterations of hArg level in the media could be explained by the fact that hArg is poorly used in metabolic pathways and completely released to the media, unlike ornithine, citrulline, and alanine (Hou et al., 2016). The relatively high correlation between the profiles of hArg and ornithine, but not citrulline, confirms that the AGAT reaction could be considered a primary origin of hArg.

\section{Conclusion}

In the present study, we suggest that hArg and ornithine could serve as the most suitable markers for monitoring myoblast growth and differentiation compared to other amino acids and their derivatives.

\section{References}

Atzler, D., Gore, M. O., Ayers, C. R., Choe, C. U., Böger, R. H., de Lemos, J.A., McGuire, D. K., and Schwedhelm, E. 2014. Homoarginine and Cardiovascular Outcome in the Population-Based Dallas Heart Study. Arteriosclerosis Thrombosis and Vascular Biology 34:2501-2507. https:// doi.org/10.1161/ATVBAHA.114.304398

Braissant, O., Henry, H., Villard, A. M., Speer, O., Wallimann, T., and Bachmann, C. 2005. Creatine synthesis and transport during rat embryogenesis: spatiotemporal expression of AGAT, GAMT and CT1. BMC Developmental Biology 5:9. https://doi.org/10.1186/1471-213X-5-9

Burattini, S., Ferri, P., Battistelli, M., Curci, R., Luchetti, F., and Falcieri, E. 2004. C2C12 murine myoblasts as a model of skeletal muscle development: morpho-functional characterization. European Journal of Histochemistry 48:223-234. https://doi.org/10.4081/891

Carrillo-Cocom, L. M., Genel-Rey, T., Araíz-Hernández, D., López-Pacheco, F., López-Meza, J., Rocha-Pizaña, M. R., Ramirez-Medrano, A., and Alvarez, M. M. 2015. Amino acid consumption in naïve and recombinant $\mathrm{CHO}$ cell cultures: producers of a monoclonal antibody. Cytotechnology 67(5):809-820. https://doi.org/10.1007/s10616014-9720-5

Choe, C. U., Atzler, D., Wild, P.S., Carter, A. M., Böger, R. H., Ojeda, F., Simova, O., Stockebrand, M., Lackner, K., 
Nabuurs, C., Marescau, B., Streichert, T., Müller, C., Lüneburg, N., De Deyn, P. P., Benndorf, R. A., Baldus, S., Gerloff, C., Blankenberg, S., Heerschap, A., Grant, P.J., Magnus, T., Zeller, T., Isbrandt, D., and Schwedhelm, E. 2013. Homoarginine levels are regulated by L-argini ne:glycine:amidinotransferase and affect stroke outcome: results from human and murine studies. Circulation 128:1451-1461. https://doi.org/10.1161/CIRCULATIONAHA. 112.000580

Cullen, M. E., Yuen, A. H., Felkin, L. E., Smolenski, R. T., Hall, J. L., Grindle, S., Miller, L. W., Birks, E.J., Yacoub, M. H., and Barton, P.J. 2006. Myocardial expression of the arginin e:glycine:amidinotransferase gene is elevated in heart failure and normalized after recovery: potential implications for local creatine synthesis. Circulation 114:16-20. https://doi.org/10.1161/CIRCULATIONAHA.105.000448

Davids, M., Ndika, J.D.T., Salomons, G.S., Blom, H.J., and Teerlink, T. 2012. Promiscuous activity of arginine:gl ycine:amidinotransferase is responsible for the synthesis of the novel cardiovascular risk factor homoarginine. Federation of European Biochemical Societies Letters 586:3653-3657. https://doi.org/10.1016/j.febslet.2012.08.020

Drechsler, C., Meinitzer, A., Pilz, S., Krane, V., Tomaschitz, A., Ritz, E., März, W., and Wanner, C. 2011. Homoarginine, heart failure, and sudden cardiac death in haemodialysis patients. European Journal of Heart Failure 13(8):852-859. https://doi.org/10.1093/eurjhf/hfr056

Henderson, J.W., Ricker, R. D., Bidlingmeyer, B.A., Woodward, C. 2000. Rapid, accurate, sensitive and reproducible HPLC analysis of amino acids. Agilent Pub 5980-1193 E

Hong, P., Wheat, T.E., Mazzeo, J.R., and Diehl, D. M. 2007. Monitoring cell culture media with the Waters amino acid analysis solution. Waters Applications Notebook $720002381 \mathrm{EN}$

Hou, Y., Jia, S., Nawaratna, G., Hu, S., Dahanayaka, S., Bazer, F. W., and Wu, G. 2015. Analysis of L-homoarginine in biological samples by HPLC involving precolumn derivatization with o-phthalaldehyde and $\mathrm{N}$-acetylL-cysteine. Amino acids 47(9):2005-2014. https://doi. org/10.1007/s00726-015-1962-9

Hou, Y., Hu, S., Jia, S., Nawaratna, G., Che, D., Wang, F., Bazer, F. W., and Wu, G. 2016. Whole-body synthesis of L-homoarginine in pigs and rats supplemented with L-arginine. Amino Acids 48(4):993-1001. https://doi. org/10.1007/s00726-015-2145-4

Keire, P., Shearer, A., Shefer, G., and Yablonka-Reuveni, Z. 2013. Isolation and culture of skeletal muscle myofibers as a means to analyze satellite cells. Methods Mol Bio/ 946:431468. https://doi.org/10.1007/978-1-62703-128-8_28

März, W., Meinitzer, A., Drechsler, C., Pilz, S., Krane, V., Kleber, M.E., Fischer, J., Winkelmann, B.R., Böhm, B. O., Ritz, E., and Wanner, C. 2010. Homoarginine, cardiovascular risk, and mortality. Circulation 122(10):967-975. https://doi.org/10.1161/CIRCULATIONAHA.109.908988

Salazar, A., Keusgen, M., and von Hagen, J. 2016. Amino acids in the cultivation of mammalian cells. Amino Acids 48(5):1161-1171. https://doi.org/10.1007/s00726-0162181-8

Sandell, L. L., Guan, X. J., Ingram, R., and Tilghman, S. M. 2003. Gatm, a creatine synthesis enzyme, is imprinted in mouse placenta. Proceedings of the National Academy of Sciences of the United States of America 100(8):4622-4627. https://doi.org/10.1073/pnas.0230424100

Van Pilsum, J. F., Stephens, G. C., and Taylor, D. 1972. Distribution of creatine, guanidinoacetate and the enzymes for their biosynthesis in the animal kingdom. Implications for phylogeny. Biochemical Journal 126:325-345. https:// doi.org/10.1042/bj1260325

Yaffe, D. and Saxel, O. 1977. A myogenic cell line with altered serum requirements for differentiation a myogenic cell line with altered serum requirements for differentiation. Differentiation 7(3):159-166. https://doi. org/10.1111/j.1432-0436.1977.tb01507.x 